\title{
Sustainability of polymer composites and its critical role in revolutionising wind power for green future
}

\author{
Sharath P. Subadra1, Paulius Griskevicius ${ }^{2}$ \\ Department of Mechanical Engineering, Kaunas University of Technology, Kaunas, Lithuania \\ ${ }^{1}$ Corresponding author \\ E-mail: ${ }^{1}$ sharath.peethambaran@ktu.edu, ${ }^{2}$ paulius.griskevicius@ktu.lt
}

Received 2 April 2021; accepted 12 April 2021

DOI https://doi.org/10.21595/stge.2021.21974

Check for updates

Copyright (C) 2021 Sharath P. Subadra, et al. This is an open access article distributed under the Creative Commons Attribution License, which permits unrestricted use, distribution, and reproduction in any medium, provided the original work is properly cited.

\begin{abstract}
Fibre reinforced polymer composites are gaining wide acceptability in different sectors due their high specific mechanical properties. They have effectively replaced conventional material like metals in many applications thus imparting lighter weight with higher efficiency. Wind energy sector has grown tremendously over the last decade and as per "The Global Wind Turbine Market-Forecasts from 2020 to 2025", global wind turbine market was valued at US\$ 90.144 billion in 2019 and is expected to grow at a CAGR of $5.34 \%$ to reach an estimated market size of US $\$ 123.154$ billion by 2025 . Wind turbine blades are fabricated using fibre reinforced composites with ideally a balsa or foam core. The composites used in this case are essentially glass reinforced in epoxy resins, and these highly engineered materials are difficult to recycle as epoxy is a thermoset resin and are not re-mouldable. This poses an environmental problem and a loss in terms of recoverable capital. Thermoplastics as against thermosets could be an alternative resin material for the blades but this has been less explored by the wind sector. The use of thermoplastic could impart cost reductions due to shorter manufacturing cycle times, recovery of raw materials and reduced tooling adjustments in terms of heating. Recovery of composite constituent parts can provide economic benefits because those constituent parts have high embedded energy. In the context of this dilemma of recyclability of wind turbine blades, this review paper intent to explore the current research and future prospect of recycling wind turbine blade materials.
\end{abstract}

Keywords: polymer composites, thermosets, thermoplastics, wind turbines, recycling, green economy.

\section{Introduction}

Fibre reinforced polymer composites are characterised by their higher strength and lower weight which has made them an ideal replacement where metals were used historically especially in the transport sector to significantly reduce the energy consumption and hence reduce the environmental fallout. Three types of composites found in general application are polymer-matrix composites (PMC), metal-matrix composites (MMC) and ceramic-matrix composites (CMC). Based on the reinforcements composites are classified into particulate composites, fibre-reinforced composites and structural composites. Polymer based composites dominates the market and thermosets are the most widely used [1].

Based on a recent market survey by Grand View Research (India \& U.S. based market research and consulting company), the composites market size which stood at UD\$ 89.04 billion in 2019 is expected to grow at a compounded annual growth rate (CAGR) of 7.6 \% from 2020 until 2027. Automotive sector is poised to drive this growth fuelled by a demand for lightweight fuel-efficient vehicles. Aerospace sector is another sector that will lead the growth in composites, especially to be used in aircraft, rockets, satellites, and missiles. Constituent wise, glass fibres where the most widely used fabric in 2019 which accounted for $61.8 \%$ of the revenues. While the same report suggested a robust growth in the carbon fabric segment with a CAGR of $7.6 \%$ from 2020 to 2027 . Resins form an important constituent, and thermosetting resins dominate the market contributing 
$72 \%$ of the revenues in 2019 the demand driven by transportation and defence sectors.

As mentioned earlier, thermosetting resins dominate the market and this is true of the wind turbine industry, used in the vacuum infusion of blades. The industry has been hesitant using thermoplastic resins though other sectors are gradually using them, but there is a growing interest on these resins within the wind sector [2]. Typically wind turbine blades are made of reinforcements of fibres (glass or carbon) in plastic polymer such as epoxy, with balsa wood or polyvinyl chloride (PVC) as sandwich core materials and bonded joints, coatings and lightning conductors (fig 1). Wind turbines are estimated to have life cycle of about 25 years and there exist a concern as to what to do with them post expiry [3].

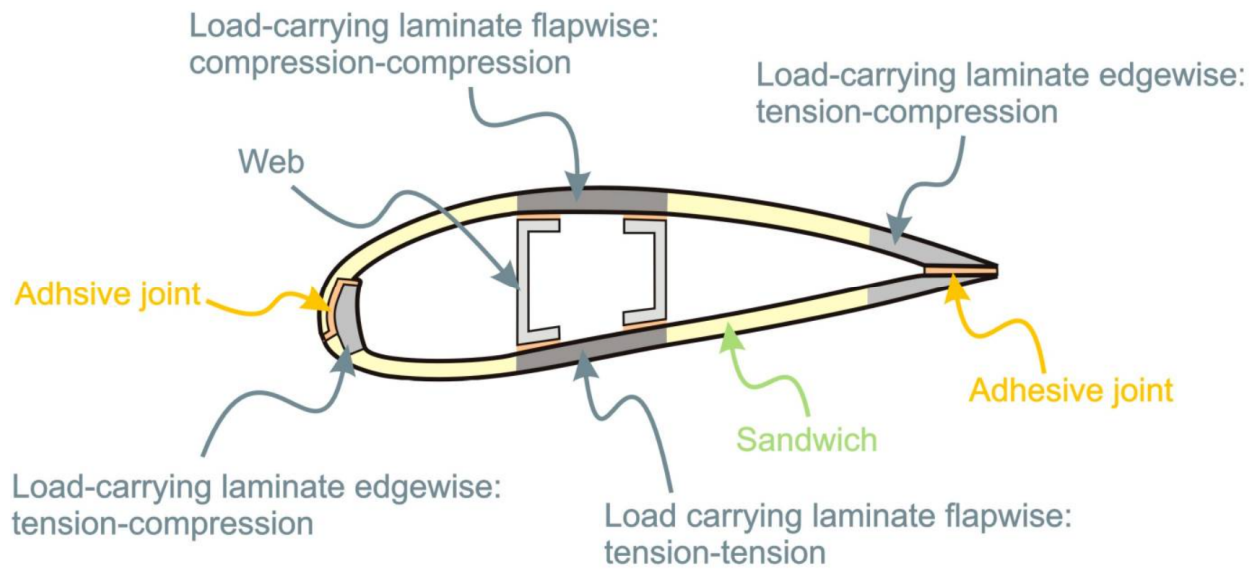

Fig. 1. Wind turbine profile showing its parts and load carrying parts [4]

Professor Henning Albers from the Institute für Umwelt und Biotechnik (Hochschule Bremen, Germany) estimated that for each $1 \mathrm{~kW}$ installed an equivalent of $10 \mathrm{~kg}$ of rotor blade material would be required. This means a $7.5 \mathrm{MW}$ turbine would require 75 tonnes of material! The associated problems concerns with recycling of the wind turbine blade constituent materials, and as per experts since the sector is quite young, there exists only limited amount of practical knowledge and experience on recycling of the turbines and it takes considerable amount of time to gain experience in dismantling, separation, recycling, and disposal of the system constituent parts [3]. In the context of retiring wind turbines, it was estimated that between 3.9 and $4.8 \mathrm{GW}$ will be decommissioned and most of these are expected to be in Denmark, Germany, the Netherlands, Spain, and Italy (Wind Europe 2019). Around the year 2022, an expected amount of 50,000 tonnes of end-of-life blades is to be handled [5]. In the same parlance a global cumulative waste from retiring wind turbine blades is estimated to be at $43,400,000$ tonnes by 2050 considering 20 years lifetime without considering the offshore wind turbines [5]. Therefore, this paper intents to review existing literature on current techniques on recycling wind turbine blades and looking into alternative materials that could make the recycling more sustainable.

\section{Current techniques available to recycle wind turbine blades}

There are a few technologies available to recycle thermoset composites that go into the manufacture of wind turbine blades and they could be put under the broad category of mechanical, thermal and chemical recycling [6-8]. Each of these methods are further elaborated in the following sub-sections.

\subsection{Mechanical recycling}

This method involves the use of crushed waste composites as raw material for secondary raw 
materials. Thus, in the context of wind turbine blade this involves pre-cutting and crushing. This recycling method is classified into two basic methods/process, the first method involves breaking up the waste into particles of fine powder while the second method is to shred/crush the waste and the recycled material obtained by the two methods are used as fillers/reinforcements or as raw materials that go into cements/concrete. Few researchers used these techniques for instance, Palmer et al. [9] tried a closed-loop recycling on thermoset composites where in, the material was grinded and later used the recycled GFRP as an ideal replacement for pristine composites. Rotor blades with glass fibre reinforced thermosetting resin was recycled through the mechanical method and used in cement production [10]. On a whole mechanical recycling method is economical and simple and is widely used in recycling of fibre reinforced polymer composites. But on the downside the final product obtained through this method is of low value due to the material especially the fibre being damaged during the recovery process and the process's inability to deliver longer fibres [2].

\subsection{Thermal recycling}

This method is further classified into three types namely, pyrolysis, fluidized bed recycling process and microwave pyrolysis. The first type essentially involves recovering fibres by decomposing the resin into organic small molecules using inert gas heat. Thus, clean fibres can be obtained by pyrolysis and oxidation and could be subsequently used as reinforcements and can compete with pristine new fibres [11]. Carbon fibres were found to be suitable for this process vis-à-vis the pristine quality of the fibres obtained after pyrolysis but Thomason et al. (2014) found that the strength of the glass fibre after pyrolysis was reduced significantly and there was limited strength re-generation from acid and silane post-treatments of the fibres. Fluidised bed method involves using air as fluidising gas in a fluidised bed reactor to decompose the matrix material through high temperature air heat flow and the heat thus generated recycles the fibre material. This method too has been found to degrade the glass fibre strength by about $50 \%$ [12]. The last documented method under this category is the microwave pyrolysis which decomposes the resin in the composite material by microwave radiation in the microwave cavity. The resin could also be internally heated by absorbing microwave energy from the fibre which then decompose the resin faster. This method was found to be suitable for carbon fabric composites [13, 14].

\subsection{Chemical recycling}

This method involves the use of chemicals to chemically modify or decompose to make waste into materials that can be recycled. This method when used to recycle thermoset matrix composites is found to be harder and more expensive but the recycling per se is better vis-à-vis the mechanical method. Supercritical fluid method and solvolysis method are the two important methods under this recycling method. The first method refers to a special state in which the temperature and pressure of the fluid exceeds that of its critical temperature and pressure. At this stage, the fluid could decompose/degrade polymer waste, and water or alcohol is used as the decomposition medium [15]. In the context of this method Oliveux et al. recycled GFRP using subcritical water and it was seen that washing of the recycled GF contaminated by residual organic substance was necessary [16]. This method is advantageous on the virtue of it being a clean and less polluting method, in addition to its ability to reproduce clean and good performance fibres. But this method requires high temperature and high pressure and thus adding to the cost of equipments that can withstand such conditions. The solvolysis method involves de-polymerisation of the polymer using the chemical properties of the solvent under heating conditions. This method is good at obtaining carbon fibres from composites [17-19], the strength of the fibre was found to be good. This method has its drawback in the form of using toxic solvents and is expensive. 


\section{Alternatives for wind turbine blades and the sustainability of recycling methods}

Thermoplastic resins are gaining acceptability as a replacement to thermoset resins in the fabrication of composite panels for various applications. As explained in the previous sections recycling thermosets are limited by its commercial exploitability on a large scale, this also reveals the small margins on which they operate. In this context thermoplastics can limit the extent of downcycling that thermosets require [20-21]. With the development of infusible thermoplastic resins for the blades, there exists a potential for recycling being more sustainable [22]. $40 \%$ of the costs of a wind turbine blade come from the labour cost and this cost is linked to the cycle time, thus by replacing thermoset with thermoplastic in the manufacturing process, there exists a possibility to reduce the cycle time [23]. This could be attributed to the polymerisation process associated with thermoplastic resins, which is its ability to polymerise at room temperature and thus eliminating heated tooling and ovens for post cure $[24,25]$. Thermoplastics can lend itself to be reformed by the application of heat thus enabling maintenance by not degrading the material properties [26]. This particular property of mouldability enables blades components to be thermally bonded without the need for separate adhesives [27]. Subadra et al. (2020) studied the impact performance of Poly methyl methacrylate (PMMA) and it was seen that they had similar impact resistance vis-à-vis epoxy resins [28]. In the context of these natural advantages, recently there is a growing interest in acrylic thermoplastic resin commercially known as Elium by Arkema which lends itself to large scale re-cycling of wind turbine blade components. Following two sections deals with Elium's capability to lends itself to be more sustainable vis-à-vis recycling and being as structurally sturdy as thermoset resin-based blade structure.

\subsection{Thermoplastic as a suitable re-placement for thermoset resin}

A wind turbine blade was manufactured using Elium as the resin by National Wind Technology Centre (NWTC) at National Renewable Energy Laboratory (NREL) in Denver, USA by R. E. Murray et al (2021). This blade was compared structurally (both static and fatigue) with an epoxy blade manufactured by TPI Composites. The thermoplastic blade was able to polymerise at room temperature and there was no requirement for a pre-heated or post-cure equipment thus reducing the manufacturing complexity and hence the costs. It was observed that the thermoplastic blade had a 3-11\% more displacement under the same static-load and this was attributed to differences in the fibreglass weight between the two blades and the adhesive used, though the thermoplastic blade was more flexible than its epoxy counterpart.

Fatigue test on both blades revealed less than $0.5 \%$ variation in stiffness over a million cycles of loading, with no large scale observable degradation in structural or material properties degradation. Both the blade types had natural frequencies within $2.5 \%$ in both the flatwise and edgewise directions while the thermoplastic blade had 5 to 7 times more structural damping. With these structural performances, which is on par with epoxy blades, Elium could serve as an ideal replacement for epoxy thus making recyclability of blade material a real possibility and hence making wind energy more sustainable part of the energy basket [29].

\subsection{Recycling thermoplastic}

The investigation carried out by D. S. Cousins et al. (2019). highlights the feasibility of using Elium since it can facilitate the recycling of wind turbine parts on a larger scale. In his study four recycling techniques were implemented namely, thermal decomposition of the polymer matrix, mechanical grinding, thermoforming, and dissolution. While thermal decomposition forms a process classified under the thermal recycling method, mechanical grinding and dissolution are classified under the broad category of mechanical and chemical recycling methods, respectively. Thermoforming involves heating thermoplastic composite sheets above the glass transition temperature of the polymer so that the shape can be altered in mould. Based on these four methods 
the research team weighed in the pro and cons of these methods vis-à-vis the recycled material.

Thermal decomposition (pyrolysis) required less energy to decompose the polymer matrix from the composites when compared to other recovery techniques. But the loss of the high-embedded-energy polymer could be counted as a disadvantage when this method is considered. Thermoplastic resin has an edge over its thermoset counterparts because the resin can be recovered by dissolution. In addition to this the glass fibre rovings recovered from the composite by this method retained its tensile strength with a reduction of only $12 \%$, while the mechanical property reduction was significant when pyrolysis (thermal decomposition) was employed to recover the fabric. Thermoforming enabled the straightening of a spar cap thus demonstrating the ability of thermoplastic composites ability to be downcycled into other products. An economic analysis on the feasibility of recycling thermoplastic composites and the recovery of the constituent materials revealed that they can replace the virgin materials within the supply chain. And a meaningful reduction in labour costs, obtaining a minimal knockdown on the polymer, and maximising the glass fibre for resale can be realised [22].

Thus, the possibility of up-scaling established recycling methods is a real time possibility. Adopting these methods, gradual replacement of thermosets and further validating its feasibility could pave the way for a fully integrated industrial cycle beginning with blade structure fabrication, installing them, recycling them and further reusing them in the same blade structure. Finally, an attempt towards green economy and an industry that is sustainable could be realised in the context of wind turbine sector.

\section{Conclusions}

The review paper explored the various recycling methods/processes developed and adopted for the recycling of thermoset matrix composites and its sustainability in the context of wind turbine blades. The three main methods namely mechanical, thermal and chemical methods were elaborated with an emphasis on its feasibility. Thermoplastic composites were discussed and its ability to lend itself to recycling was stressed and the ability of the novel resin by Arkema, Elium was discussed. Elium's ability to replace thermoset matrix in wind turbine blades and its ability to sustains loads both static and dynamic was studied and later the ability of this thermoplastic to be recycled was also seen. Thermoplastics can replace the conventional thermosets albeit in a gradual manner as some thermoplastics can bear similar loads as the one bore by the thermosets and this has been proven through two case studies in this paper. Similarly, more studies should be carried out studying the ability and feasibility of these thermoplastics especially Elium which has PMMA as its constituent polymer. The ability of this resin to lend itself to conventional recycling methods can be a better option vis-à-vis epoxy-based composites. Thus, the wind turbine sector could gradually mature into a sector on par with conventional material sector and thus making composites more environmentally sustainable.

\section{References}

[1] Yang Y., Boom R., Irion B., Heerden Kuiper Wit D. J. P. H. Recycling of composites materials. Chemical Engineering and Processing: Process Intensification, Vol. 51, 2012, p. 53-68.

[2] Chen J., Wang J., Ni A. Recycling and reuse of composite materials for wind turbine blades: An overview. Journal of Reinforced Plastics and Composites, Vol. 38, 2019, p. 567-577.

[3] Larsen K. Recycling wind turbine blades. Renewable Energy Focus, Vol. 9, 2009, p. 70-73.

[4] Mishnaevsky Jr L., Branner K., Petersen H. N., Beauson J., Mcgugan M., Sørensen F. Materials for wind turbine blades: An overview. Materials, Vol. 10, 2017, p. 1285.

[5] Liu P., Barlow C. Y. Wind turbine blade waster in 2050. Waste Management, Vol. 62, 2017, p. 229-240.

[6] Beauson J., Lilholt H., Brøndsted P. Recycling solid residues recovered from glass fibre-reinforced composites-a review applied to wind turbine blade materials. Journal of Reinforced Plastic Composites, Vol. 33, 2014, p. 1542-1556. 
[7] Pickering S. J. Recycling technologies for thermoset composite materials-current status. Composite A, Vol. 37, 2006, p. 1206-1215.

[8] Pimenta S., Pinho S. T. Recycling carbon fibre reinforced polymers for structural application: technology review and market outlook. Waste Manage, Vol. 31, 2011, p. 378-392.

[9] Palmer J., Ghita O. R., Savage L. Successful closed loop recycling of thermoset composites. Composite A, Vol. 40, 2009, p. 490-498.

[10] Schmidl E., Hinrichs S. Geocycle provides sustainable recycling of rotor blades in cement plant. Dewi Magazine, Vol. 36, 2010, p. 6-14.

[11] Giorgini L., Leonardi C., Mazzocchetti L. Pyrolysis of fibreglass/polyester composites: recovery and characterisation of obtained products. FME Transactions, Vol. 44, 2016, p. 405-414.

[12] Pickering S. J., Kelly R. M., Kennerley J. R. A fluidised-bed process for the recovery of glass fibres from scrap thermoset composites. Composites Science Technology, Vol. 60, 2000, p. 509-523.

[13] Mcconnell V. P. Launching the carbon fibre recycling industry. Reinforced Plastic, Vol. 54, 2010, p. 33-37.

[14] Lester E., Kingman S., Wong K. H. Microwave heating as a means for carbon fibre recovery from polymer composites: a technical feasibility study. Materials Research Bulletin, Vol. 39, 2004, p. $1549-1556$.

[15] Okajima I., Sako T. Recycling of carbon fibre reinforced plastic using supercritical and subcritical fluids. Journal of Mater Cycles Waste Management, Vol. 19, 2015, p. 15-20.

[16] Oliveux G., Bailleul J. L., Salle E. L. G. L. Chemical recycling of glass fibre reinforced composites using subcritical water. Composites A, Vol. 43, 2012, p. 1809-1818.

[17] Xu P., Li J., Ding J. Chemical recycling of carbon fibre/epoxy composites in a mixed solution of peroxide hydrogen and N,N-dimethylformamide. Composite Science and Technology, Vol. 82, 2013, p. 54-59.

[18] Jiang Y., Deng G., Chen X. On the successful chemical recycling of carbon fibre/epoxy resin composites under the mild condition. Composite Science and Technology, Vol. 151, 2017, p. 243-251.

[19] Wang Y., Cui X., Ge H. Chemical recycling of carbon fibre reinforced epoxy resin composites via selective cleavage of the carbon-nitrogen bond. ACS Sustainable Chemistry and Engineering, Vol. 3, 2015, p. 3332-3337.

[20] Li X., Bai R., Mckechnie J. Environmental and financial performance of mechanical recycling of carbon fibre reinforced polymers and comparison with conventional disposal routes. Journal of Clean Production, Vol. 127, 2016, p. 451-460.

[21] Witik R. A., Teuscher R., Michaud V., Ludwig C., Månson J. Carbon fibre reinforced composite waste: an environmental assessment of recycling, energy recovery and landfilling. Composites Part A: Applied Science and Manufacturing, Vol. 49, 2013, p. 89-99.

[22] Cousins D. S., et al. Recycling glass fibre thermoplastic composites from wind turbine blades. Journal of Clean Production, Vol. 209, 2019, p. 1252-1263.

[23] Murray R. E., et al. Techno-economic analysis of a megawatt-scale thermo-plastic resin wind turbine blade. Renewable Energy, Vol. 131, 2019, p. 111-119.

[24] Rijswijk Van K., Bersee H. E. N. Reactive processing of textile fibre-reinforced thermoplastic composites-an overview. Composites Part A: Applied Science and Manufacturing, Vol. 38, 2007, p. 666-681.

[25] The composites Institute facilities thermoplastic composite development for wind turbine blades through innovative project. IACMI, 2017, http://iacmi.org/2017/01/17/iacmi-composites-insitutefacilties-thermoplastic-composite-developement-wind-turbine-blades-innovative-project/.

[26] Rijswijk van K., et al. Sustainable vacuum-infused thermoplastic composites for MW-size wind turbine blades-preliminary design and manufacturing issues. Journal of Solar Energy Engineering, Vol. 127, Issue 4, 2005, p. 570-580.

[27] Murray R. E., Roadman J., Beach R. Fusion joining of thermoplastic composite wind turbine blades: lap-shear bond characterization. Renewable Energy, Vol. 140, 2019, p. 501-512.

[28] Subadra S. P., Griskevicius P., Yousef S. Low velocity impact and pseudo-ductility behaviour of carbon/glass/PMMA hybrid composite laminates for aircraft application at service temperature. Polymer Testing, Vol. 89, 2020, p. 106711.

[29] Murray E. R., et al. Structural validation of a thermoplastic composite wind turbine blade with comparison to a thermoset composite blade. Renewable Energy, Vol. 164, 2021, p. 1100-1107. 
Sharath P. Subadra current Ph.D. student at Kaunas University of Technology, Department of Mechanical Engineering. His current research interests Polymer composites damage modelling.

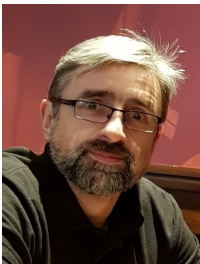

Paulius Griskevicius hold a Ph.D. degree from Kaunas University of Technology. Now he works KTU as an Associate Professor. His current research includes polymer composite with non-destructive test methods to detect damage in polymer composites. 